\title{
ARTICLE Pituitary adenylate cyclase-activating polypeptide (PACAP) modulates dependence-induced alcohol drinking and anxiety- like behavior in male rats
}

\author{
Antonio Ferragud (D) ${ }^{1}$, Clara Velazquez-Sanchez ${ }^{1}$, Margaret A. Minnig ${ }^{1}$, Valentina Sabino ${ }^{1}$ and Pietro Cottone ${ }^{1}$
}

\begin{abstract}
Alcohol use disorder (AUD) is a devastating illness defined by periods of heavy drinking and withdrawal, often leading to a chronic relapsing course. Initially, alcohol is consumed for its positive reinforcing effects, but later stages of AUD are characterized by drinking to alleviate withdrawal-induced negative emotional states. Brain stress response systems in the extended amygdala are recruited by excessive alcohol intake, sensitized by repeated withdrawal, and contribute to the development of addiction. In this study, we investigated one such brain stress response system, pituitary adenylate cyclase-activating polypeptide (PACAP), and its cognate receptor, PAC1R, in alcohol withdrawal-induced behaviors. During acute withdrawal, rats exposed to chronic intermittent ethanol vapor (ethanol-dependent) displayed a significant increase in PACAP levels in the bed nucleus of the stria terminalis (BNST), a brain area within the extended amygdala critically involved in both stress and withdrawal. No changes in PACAP levels were observed in the central nucleus of the amygdala. Site-specific microinfusion of the PAC1R antagonist PACAP(6-38) into the BNST dose-dependently blocked excessive alcohol intake in ethanol-dependent rats without affecting water intake overall or basal ethanol intake in control, nondependent rats. Intra-BNST PACAP(6-38) also reversed ethanol withdrawal-induced anxiety-like behavior in ethanol-dependent rats, but did not affect this measure in control rats. Our findings show that chronic intermittent exposure to ethanol recruits the PACAP/PAC1R system of the BNST and that these neuroadaptations mediate the heightened alcohol drinking and anxiety-like behavior observed during withdrawal, suggesting that this system represents a major brain stress element responsible for the negative reinforcement associated with the "dark side" of alcohol addiction.
\end{abstract}

Neuropsychopharmacology (2021) 46:509-518; https://doi.org/10.1038/s41386-020-00904-4

\section{INTRODUCTION}

Alcohol use disorder (AUD) affects 76 million people worldwide and is characterized by uncontrolled heavy drinking and a chronic relapsing course. While alcohol is initially consumed for its positive reinforcing effects, the later stages of AUD are characterized by drinking to alleviate the withdrawal-induced "hyperkatifeia" or negative emotional state, via a negative reinforcement mechanism [1-4]. Disrupting the cycle of excessive drinking due to negative affective states during withdrawal may, therefore, represent a promising strategy in the treatment of AUD $[3,5]$.

Chronic alcohol exposure and withdrawal have been shown to alter the function and plasticity of neurons of the bed nucleus of the stria terminalis (BNST), a brain structure critically involved in the behavioral response to sustained stress as well as in the negative affective state associated with chronic alcohol use [6-12]; the BNST has also been shown to play a role in the sensitization of ethanol withdrawal-induced anxiety-like behavior [13]. Specific brain stress systems are recruited in the BNST by excessive alcohol intake and contribute to the development of addiction via the establishment of negative reinforcement during withdrawal $[3,14]$; these include corticotropin-releasing factor (CRF), norepinephrine, and serotonin, among others [15-19].
Pituitary adenylate cyclase-activating polypeptide (PACAP) and its cognate receptor (PAC1R) have been proposed to be key mediators of the stress response [20-23], and are heavily expressed in the dorsolateral BNST in both humans and rodents [24, 25]. Dense PACAP-immunoreactive fibers are found in both the dorsolateral BNST (oval nucleus) and in the capsular and lateral parts of the central amygdala (CeA) subdivision, generally believed to be of mostly nonlocal origination [26-29]. PACAP administration into structures of the extended amygdala has been shown to induce a stress-response and to activate CRF systems [21, 28, 30, 31]. In addition, acute and chronic stressors increase PACAP expression within the BNST [31, 32]. Notably, the response to previous stress exposure, as measured physiologically and behaviorally, is also attenuated by intra-BNST PAC1R antagonism [31, 33].

In humans, a single nucleotide polymorphism of the PACAP encoding gene has been related to enhanced alcohol intake in a population of European adults [34], while a specific genotype of the PAC1R was associated with problematic alcohol use in women [35], suggesting its potential involvement in AUD. The PACAP/ PAC1R system has been linked to the actions of drugs of abuse and alcohol [36-38]. Other studies have shown that global PACAP knockout mice display higher sensitivity to ethanol-induced ataxia

\footnotetext{
'Laboratory of Addictive Disorders, Departments of Pharmacology and Experimental Therapeutics and Psychiatry, Boston University School of Medicine, Boston, MA, USA Correspondence: Valentina Sabino (vsabino@bu.edu) or Pietro Cottone (cottone@bu.edu)

These authors contributed equally: Valentina Sabino, Pietro Cottone.
}

Received: 16 June 2020 Accepted: 23 October 2020

Published online: 16 November 2020 
[39], higher preference for ethanol, and reduced ethanol-induced hypothermic and hypnotic effects [40, 41]. Intermittent ethanol exposure has been shown to increase PACAP in the paraventricular nucleus of the thalamus and acute ethanol exposure to increase PAC1R mRNA expression in cell lines $[42,43]$. Recently, the PACAP/ PAC1R system of the BNST has also been shown to regulate stressinduced reinstatement of cocaine seeking behavior [44].

Given the literature suggesting a possible role of PACAP in human AUD, the observation that PAC1R antagonists have anxiolytic-like properties, and the fact that PACAP and PAC1Rs are highly expressed in the BNST, we investigated whether the PACAP/PAC1R system of the BNST plays a role in the increased alcohol intake and anxiety-like behavior associated with ethanol dependence. Our hypothesis was that the PACAP/PAC1R system of the BNST represents a major brain stress element responsible for the negative reinforcement associated with alcohol withdrawal and the "dark side" of addiction. We first assessed PACAP immunoreactivity in the BNST during acute ethanol withdrawal in rats exposed to chronic intermittent ethanol (CIE) vapor, a wellestablished model of ethanol dependence. We then utilized sitespecific microinfusions of the PAC1R antagonist PACAP(6-38) in the BNST to test the functional relevance of the molecular changes in withdrawal-induced alcohol intake and anxiety-like behavior. Our data suggest that the recruitment of the PACAP/ PAC1R system is involved in the transition from limited ethanol use to ethanol dependence and in the associated negative emotional state.

\section{MATERIAL AND METHODS}

\section{Subjects}

Male Wistar rats (total $n=41$ ) weighing $225-250 \mathrm{~g}$ upon arrival (Charles River, Wilmington, MA, USA) were housed in an AAALACapproved vivarium on a 12-h light-dark cycle (lights off at 11:00 am), with water and regular rodent corn-based chow (Harlan Teklad Diet 7012) available ad libitum. Experiments were conducted during the rats' dark cycle. Procedures adhered to the National Institutes of Health Guide for the Care and Use of Laboratory Animals and the Principles of Laboratory Animal Care and were approved by Boston University Medical Campus Institutional Animal Care and Use Committee.

\section{Drugs}

Ethanol solution $(10 \% \mathrm{w} / \mathrm{v})$ was prepared using $95 \%$ ethyl-alcohol and tap water. PACAP(6-38) was purchased from the American Peptide Company (Sunnyvale, CA). The peptide was dissolved in sterile isotonic saline in the presence of $0.1 \%$ bovine serum albumin (Sigma Aldrich, St. Louis, MI). PACAP(6-38) doses were chosen based on previous reports [45-47] and were administered 30 min before the tests.

\section{Apparatus for operant oral ethanol self-administration}

The test chambers used for operant oral self-administration (Med Associates, Inc., St. Albans, VT) were located in sound-attenuating, ventilated cubicles $(66 \times 56 \times 36 \mathrm{~cm})$. Syringe pumps (Med Associates, St. Albans, VT) dispensed ethanol or water into two stainless steel drinking cups mounted $2 \mathrm{~cm}$ above the grid floor in the middle of one side panel. Two retractable levers were located 3.2 $\mathrm{cm}$ to either side of the drinking cups. Fluid delivery and operant responses were controlled by microcomputers.

\section{Self-administration procedure}

Rats $(n=20)$ were subjected first to $1-3$ overnight sessions ( $16 \mathrm{~h}$ ) of two-choice operant access to $10 \% \mathrm{w} / \mathrm{v}$ ethanol and water with chow available ad libitum. Thereafter, they were trained in ethanol operant intake using daily 30 -min sessions under a fixed ratio schedule (FR1) as previously described [48]. Right lever responses resulted in the delivery of $0.1 \mathrm{ml}$ of ethanol, while left lever responses delivered $0.1 \mathrm{ml}$ of water. After baseline stabilization, as defined by $<20 \%$ variability across 3 consecutive sessions, rats were divided into two groups, matched for body weight and ethanol intake. One group received chronic, intermittent exposure to ethanol vapor (ethanol-dependent group), while the other group was exposed to room air (nondependent group or Controls).

Ethanol vapor exposure procedure

Wistar rats were housed within sealed, clear plastic chambers (La Jolla Alcohol Research, Inc, CA) into which ethanol vapor was intermittently introduced to induce dependence, as described previously [49]. A timer connected to the chambers turned the ethanol vapor on (8:00 p.m.) and off (10:00 a.m.), for a total of 14 h of daily ethanol exposure. Tail blood $(50 \mu \mathrm{l})$ was sampled at vapor offset for baseline alcohol levels (BALs) determination twice during the first week and weekly thereafter. After centrifugation, plasma was assayed for alcohol content using an oxygen-rate alcohol analyzer (Analox Instruments, Lunenburg, MA). BALs at plateau were $149.4 \pm 12.6 \mathrm{mg} / \mathrm{dl}$. This paradigm has been shown to induce physical dependence and increase operant ethanol selfadministration during withdrawal $[50,51]$. Control rats were kept under similar conditions but under room air. After 6 weeks of ethanol vapor exposure, rats resumed operant ethanol selfadministration sessions twice weekly, beginning 8-10 h after the vapor offset. The first few 30 -min sessions allow subjects to experience the negative reinforcing effects of ethanol during withdrawal. Once ethanol responding was stable $(<20 \%$ variability, see Fig. 2, sessions 1-8), the rats underwent surgery for BNSTcannula implantation. Vapor (or air) exposure continued throughout the operant self-administration sessions, such that the rats were constantly in an "acute" withdrawal state when tested.

\section{Intracranial surgery, microinfusion procedure, and cannula} placement

Intracranial surgeries. The surgical procedures were performed as previously described [52, 53]. Briefly, stainless steel, guide cannulas (24 gauge, Plastics One, Roanoke, VA, USA) were lowered bilaterally $2.0 \mathrm{~mm}$ above the BNST (AP $-0.3, \mathrm{ML} \pm 3.6$, DV -4.9 , tilt angle of $18^{\circ}$ ). Four stainless steel jeweler's screws were fastened to the rat's skull around the cannula. Dental restorative filled resin (Henry Schein, Melville, NY, USA) and acrylic cement were applied, forming a pedestal firmly anchoring the cannula. A stainless steel dummy stylet (Plastics One) maintained patency of the cannula. Following a recovery period, rats were again exposed to the alcohol vapor chambers and alcohol self-administration sessions resumed.

Microinfusion procedure. For intracranial microinfusions, the dummy stylet was removed from the guide cannula, and replaced with a 31-gauge stainless steel injector projecting $2 \mathrm{~mm}$ beyond the tip of the guide cannula, which was connected via PE-20 tubing to a Hamilton microsyringe (Hamilton, Reno, NV). Bilateral microinfusions were performed at a rate of $0.5 \mu \mathrm{l} / 2 \mathrm{~min}$ and injectors were left in place for 1 additional minute to prevent backflow. While this procedure has been extensively validated to target small brain areas, we do not exclude that the drug may have diffused to other BNST subdivisions within the dorsal BNST.

Cannula placement. At the conclusion of the experiment, subjects were anaesthetized (isoflurane, 2-3\% in oxygen) and microinfused with India Ink $(0.5 \mu \mathrm{l} / \mathrm{side})$ to verify cannula placement. Brains were quickly removed, flash-frozen, and stored at $-80 \mathrm{C}$. In these brains, there was no evidence of nonspecific brain damage (gliosis, cavitation) around the cannula tip, except for the inevitable cannula track. Coronal sections $(40 \mu \mathrm{m})$ were obtained using a cryostat, and placements were verified under a microscope (see Supplementary Fig. 1). 
Ethanol self-administration tests

After surgery, once stable performance was again reached in ethanol self-administration performance $(<20 \%$ variation), rats received PACAP $(6-38)(0,0.1,0.3,1.0$, and $3.0 \mu \mathrm{g} / \mathrm{rat})$ microinjections intra-BNST 30 min prior to the test session, using a withinsubject Latin-square design. The rats were allowed to return to baseline ethanol intake levels between test days.

\section{Light-dark conflict test}

One week after completion of the self-administration tests, the same set of rats $(n=20)$ was tested in a light-dark conflict test. The test was performed using a light/dark rectangular box $(50 \times 100 \times 35 \mathrm{~cm})$ in which the aversive, bright compartment was illuminated by a 60-lux light. The dark compartment $(50 \times 30 \times 35 \mathrm{~cm})$ had an opaque cover and $\sim 0$ lux of light. The light and dark compartments were connected by an open doorway, which allowed subjects to move freely between the two compartments. On the test day, rats were allowed to habituate in an ante-room $2 \mathrm{~h}$ prior to testing. PACAP(6-38) $(0$, $3.0 \mu \mathrm{g} / \mathrm{rat}$ ) or vehicle were administered $30 \mathrm{~min}$ before the light-dark test and order of testing counterbalanced across the four groups. The test started by placing the rat in the center of the dark compartment and closing the cover; test lasted $10 \mathrm{~min}$. The box was cleaned with a water-dampened cloth after each subject. Rat behavior was videotaped using a camera and later scored by a rater, who was blind to treatments. The percentage of time spent in the light and dark compartment was calculated for each animal, in addition to the latency to first exit the dark compartment.

PACAP and PAC1R Immunohistochemistry

Perfusions. A separate cohort of rats $(n=21)$ was exposed to either alcohol vapor or room air for 8 consecutive weeks as described above. Eight to ten hours after vapor offset, rats were anesthetized with isoflurane and transcardially perfused with phosphate-buffered saline (PBS) followed by $4 \%$ paraformaldehyde (PFA). Brains were collected, placed in 4\% PFA overnight, and then stored in $30 \%$ sucrose in PBS solution at $4{ }^{\circ} \mathrm{C}$ until saturation. Brains were cut into $30 \mu \mathrm{m}$ coronal sections using a cryostat and stored in a cryoprotectant solution at $-20^{\circ} \mathrm{C}$ until processed for immunohistochemistry (IHC).

Immunohistochemistry (IHC). Every 6th section $(180 \mu \mathrm{m}$ apart; bregma) of the rat BNST region (range: +0.12 to $-0.48 \mathrm{~mm}$ from bregma) and the CeA region (range: -1.80 to $-2.92 \mathrm{~mm}$ from bregma) were collected systematically and processed for IHC. After rinsing, free-floating sections were incubated in $0.3 \%$ hydrogen peroxide TBS solution to quench endogenous peroxidases, followed by additional rinsing and a blocking step (either $10 \%$ or $5 \%$ normal goat serum for PACAP and PAC1R, respectively, in $0.3 \%$ Triton $\mathrm{X} 100)$. Sections were then incubated in either an anti-PACAP $(1: 4,000, T-4473$, Bachem, Torrance, CA; RRID: $\left.A B \_519166\right)[26,54-61]$ or an anti-PAC1R primary antibody (1:250, sc-30018, Santa Cruz Biotechnology, Dallas, TX; RRID: AB_2305215) [62-64] in blocking solution for $24 \mathrm{~h}$ at $4{ }^{\circ} \mathrm{C}$. Sections were then rinsed and incubated in a biotinylated anti-rabbit secondary antibody (1:500, Vector Labs, Burlingame, CA) in blocking solution for $2 \mathrm{~h}$ at room temperature. Sections were washed and then incubated in an avidin-biotin horseradish peroxidase solution (Vector Labs, Burlingame, CA) and immunoreactivity was visualized using a diaminobenzidine substrate kit (Vector Labs, Burlingame, CA) according to the manufacturer's instructions. Slides were dehydrated using graded alcohol concentrations and then cover-slipped.

PACAP density measurement. To assess PACAP-immunoreactivity, bright-field objective pictures of sections containing either the lateral-dorsal subdivision or oval nucleus of the BNST (STLD) $(0.00$ to $-0.24 \mathrm{~mm}$ from bregma) and the capsular and lateral subdivisions of the $\mathrm{CeA}(\mathrm{CeC}-\mathrm{CeL})$ along the entire bregma range (see "Results" section for justification) were captured at $\times 10$ magnification under a preset exposure and gain with an Olympus BX-51 microscope (Center Valley, PA, USA) equipped with a Rotiga 2000R live video camera (QImaging, Surrey, BC, Canada) and a three-axis MAC6000 XYZ motorized stage (Ludl Electronics, Hawthorne, NY). Densitometry analysis was then performed using the ImageJ software (NIH), where images were converted to 8-bit and adjusted using the auto threshold Triangle algorithm. Internal capsule and corpus callosum were used as control areas for nonspecific DAB background for BNST and CeA, respectively. Once converted, mean density of immunohistochemical signal was obtained by subtracting the optical density of the nonspecific DAB background from the region of interest, as previously described [31]. Experimenters were blind to treatment groups. Three subjects were excluded in the CeA because of poor staining/ tissue quality.

Quantification of PAC1R-positive cell bodies. PAC1R-positive cells were quantified using an unbiased stereology approach as previously described [65]. Briefly, the medial-anterior subdivision (STMA), the lateral-posterior subdivision (STLP), and the lateraldorsal subdivision or oval nucleus (STLD) of the BNST were outlined virtually on the digitized image of each section using the optical fractionator workflow module of Stereo Investigator software (MicroBrightField,Williston, VT). One hemisphere was randomly chosen for each section; the contours of the areas of interest were drawn at $\times 10$ using an Olympus PlanApo $\mathrm{N} \times 2$ objective with numerical aperture 0.08 and counted using an Olympus UPlanFL $\mathrm{N} \times 40$ objective with numerical aperture 0.75 . A guard zone of $2 \mathrm{~mm}$ and a dissector height of $20 \mathrm{~mm}$ were used. Experimenters were blind to treatment groups. Two subjects were excluded because of poor staining/tissue quality.

\section{Statistical analysis}

Data from the IHC studies were analyzed using Student's $t$ test. Data from self-administration training was analyzed with a mixed design ANOVA, with Group as a between-subjects and Day as a within-subject factor. Data from the alcohol and water intake studies were analyzed using a two-way mixed design ANOVA with Group as a between-subjects factor and Dose as a within-subject factor. Data from the light-dark anxiety test were analyzed using a two-way ANOVA with Group and Drug Treatment as betweensubjects factors. Pairwise post-hoc comparisons were made using the Student Newman-Keuls test or a Student's $t$ test when comparing two groups only. Significance was set at $p<0.05$. The software/graphic packages used were Statistica 7.0, and SigmaPlot 11.0.

\section{RESULTS}

Chronic intermittent exposure to ethanol vapors increases PACAP levels in the BNST, but not the CeA

As shown in Fig. 1A-D, ethanol-dependent rats showed higher levels of PACAP immunoreactivity in the dorsal BNST, compared to control, nondependent rats, during acute withdrawal $(t(19)=$ $-2.12, p<0.05)$. Indeed, chronic ethanol vapor exposure resulted in a $26 \%$ increase in relative PACAP immunoreactivity in the BNST 8-10 h after vapor offset. Across the anterior-posterior axis of the BNST, the majority of PACAP immunoreactivity was found in the dorsal part of the lateral subdivision or oval nucleus (STLD), with faint staining present in the lateral juxtacapsular (STLJ) and intraamygdaloid subdivisions (STIA) [66]. The IHC staining pattern suggests that PACAP immunoreactivity was limited to incoming fibers, with very few local cell bodies labeled. No increase in PACAP immunoreactivity was observed in the $\mathrm{CeA}$ of ethanol-dependent rats compared to controls (Fig. $1 \mathrm{E}-\mathrm{H},(t(16)=0.24, \mathrm{n} . \mathrm{s}$.)). Across the anterior-posterior axis of the CeA, PACAP immunoreactivity was 
A

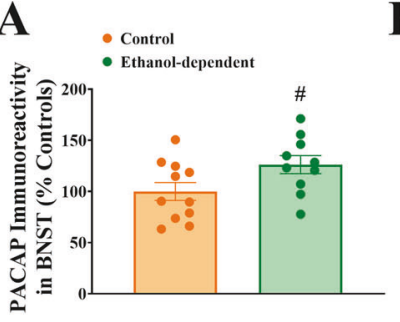

C

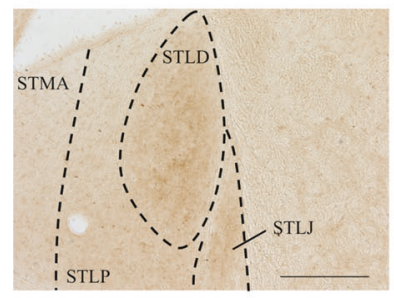

$\mathbf{E}$

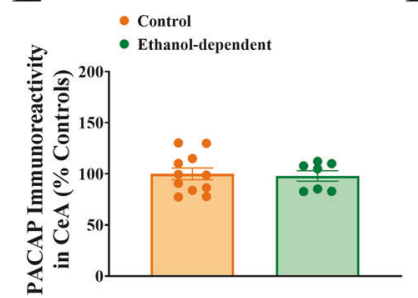

G

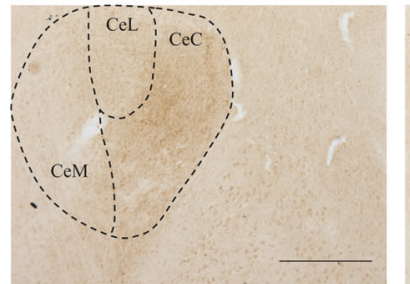

H

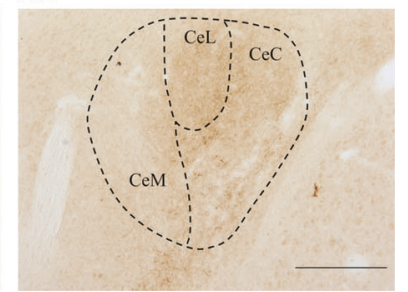

Fig. 1 Effect of chronic intermittent exposure to ethanol vapors on PACAP immunoreactivity in the BNST and in the CeA 8-10 h after vapor offset. Effect of chronic intermittent exposure to ethanol vapors on PACAP immunoreactivity in the BNST (A-D) and in the $\mathrm{CeA}(\mathbf{E}-\mathbf{H})$ 8-10 h after vapor offset. Ethanol-dependent rats showed an enhanced expression of PACAP immunoreactivity in BNST (A), but not CeA (E), compared to control, nondependent rats. Drawing of coronal rat brain slices representing the area analyzed in BNST (B) and CeA (F). Representative pictures of PACAP immunoreactivity in the BNST (C-D) and CeA (G-H) in control nondependent and in ethanol-dependent rats, respectively. STMA BNST medialanterior, STLP BNST lateral-posterior, STLD BNST lateral-dorsal, STLJ BNST lateral-justacapsular, CeM CeA medial, CeL CeA lateral, $\mathrm{CeC}$ $\mathrm{CeA}$ capsular. Scale bars represent $250 \mu \mathrm{m}$. Control and ethanoldependent rats are depicted in orange and green, respectively. Data represent Mean \pm SEM ( $n=10-11$ /group for BNST, $n=7-11 /$ group for $(\mathrm{eA}) .{ }^{\#} p<0.05$ vs. Controls.

limited to the capsular $(\mathrm{CeC})$ and lateral $(\mathrm{CeL})$ subdivisions, where PACAP staining was again suggestive of fibers. Due to the restriction of PACAP immunoreactivity to the nuclei mentioned for the CeA and BNST, densitometry was performed exclusively in these subdivisions (BNST: STLD; $\mathrm{CeA}$ : $\mathrm{CeC}$ and $\mathrm{CeL}$ ).

Chronic intermittent exposure to ethanol vapors does not affect the number of PAC1R-positive cells in the BNST

No difference in the number of PAC1R-positive cells was found in the dorsal portion of the BNST between ethanol-dependent and

control rats, during acute withdrawal $(t(17)=0.38$, n.s.) (Fig. 2). PAC1R immunoreactivity was found to be similarly present in the STMA, STLP, and STLD subdivisions, and it was not affected by CIE in any specific subdivision (STLD: $t(17)=0.53$, n.S.; STLP: $t(17)=$ 0.08 , n.s.; STMA: $t(17)=0.39$, n.s.) (Fig. $2 C, D$ ).

Chronic intermittent exposure to ethanol vapors enhances selfadministration of alcohol

Rats were divided into either a CIE vapor (Ethanol-dependent) or a Control group (controls), matched according to weight and last three baseline sessions of self-administration training prior to vapor chambers (Fig. 3, baseline sessions). Following chronic ethanol vapor exposure, ethanol-dependent rats self-administered significantly more alcohol in the eight sessions prior to the start of the pharmacological testing (Fig. 3A, B) (Group: $F(1,19)=44.39, p$ $<0.001$, Group $\times$ Session: $F(7,133)=1.17$, n.s.).

Conversely, ethanol-dependent rats did not differ from controls in the amount of water self-administered during the eight sessions (Fig. 3C, D) (Group: $F(1,19)=0.35$, n.s., Group $\times$ Session: $F(7,133)=$ 0.63 , n.s.).

Intra-BNST PAC1R antagonist PACAP(6-38) blocks excessive drinking in ethanol-dependent rats

Ethanol-dependent rats continued responding excessively for ethanol compared to control, nondependent rats (Group: $F$ $(1,18)=11.14, p<0.01)$. The intra-BNST administration of the PAC1R antagonist PACAP(6-38) selectively and dosedependently blocked excessive ethanol self-administration in ethanol-dependent rats, but not in control, nondependent rats, as reflected by a significant interaction of Group $\times$ Dose $($ Group $\times$ Dose: $F(4,72)=6.29, p<0.001$; Dose: $F(4,72)=2.65, p$ $<0.05)$, as shown in Fig. 4A, B. Post-hoc analysis revealed a significant effect of the $0.3,1$, and $3 \mu \mathrm{g}$ doses compared to vehicle condition, with a $40 \%$ reduction at the highest dose. At the highest dose, PACAP(6-38) fully blocked the excessive ethanol intake of ethanol-dependent rats as compared to their control, nondependent counterpart $(p=0.67)$. As shown in Fig. 4C, D, responding for water was unaffected by PACAP(6-38) at any of the doses tested, in either group (Group $\times$ Dose: $F$ $(4,72)=0.95$, n.s.; Dose: $F(4,72)=1.20$, n.s.). All cannula placements were verified to be within the BNST on both sides of the brain (Supplementary Fig. 1).

Intra-BNST PACAP(6-38) blocks ethanol withdrawal-induced anxiety in ethanol-dependent rats

Rats exposed to chronic, intermittent ethanol vapor showed enhanced anxiety-like behavior during the light/dark conflict test (Group: $F(1,14)=6.51, p<0.05)$. In fact, as shown in Fig. 5A, ethanol-dependent rats showed a $40 \%$ reduction of time spent in the aversive light compartment compared to controls under Vehicle conditions. The $3 \mu \mathrm{g}$ dose of PACAP(6-38) selectively blocked the vapor exposure-induced anxiety-like behavior in ethanol-dependent rats but not in controls (Group $\times$ Dose: $F(1,14)$ $=7.97, p=0.013$ ). Latency to first exit the dark compartment, as shown in Fig. 5B, indicated a trend to be increased by vapor exposure to be normalized by the antagonist which, however, did not reach statistical significance (Group: $F(1,14)=2.64, p=0.13$; Group $\times$ Dose: $F(1,14)=2.22, p=0.16)$. Number of transitions between the two compartments was not affected (Group: $F$ $(1,14)=1.56$, n.s.; Group $\times$ Dose: $F(1,14)=0.26$, n.s.) (data not shown).

\section{DISCUSSION}

The main findings of this series of studies were as follows: (i) chronic intermittent exposure to alcohol vapor increases PACAP, but not PAC1R, expression in the BNST, but not the $\mathrm{CeA}$, of rats during acute withdrawal, compared to control, nondependent 
A

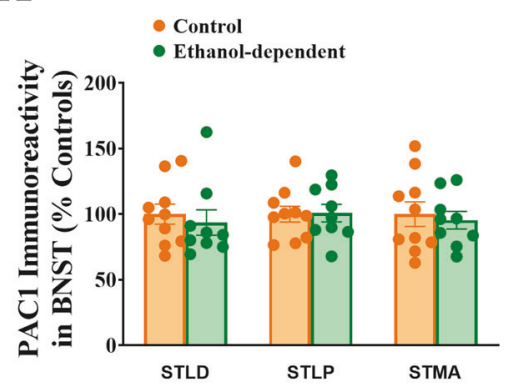

B

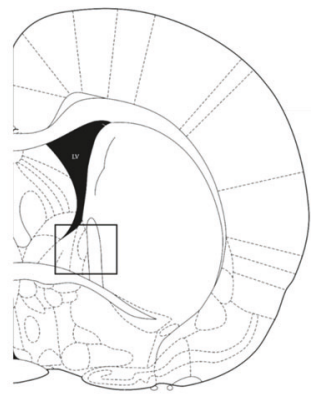

C

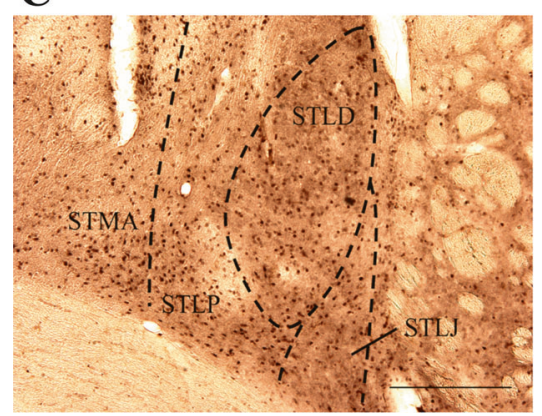

D

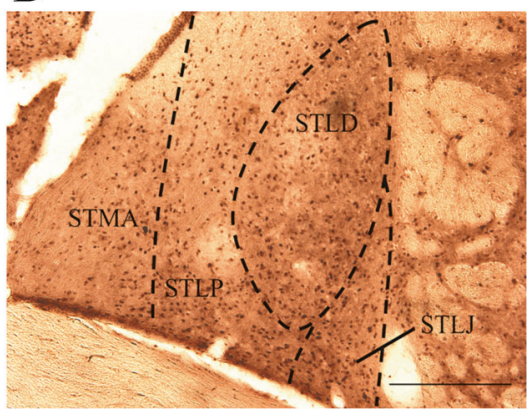

Fig. 2 Effect of chronic intermittent exposure to ethanol vapors on PAC1R-positive cell bodies in the BNST 8-10 h after vapor offset. No difference was found between groups (A). Drawing of a coronal rat brain slice representing the area analyzed (B). Representative pictures of PACAP immunohistochemistry in control, nondependent and in ethanol-dependent rats (C-D). STMA BNST medial-anterior, STLP BNST lateralposterior, STLD BNST lateral-dorsal, STLJ BNST lateral-justacapsular. Scale bars represent $250 \mu \mathrm{m}$. Control and ethanol-dependent rats are depicted in orange and green, respectively. Data represent Mean \pm SEM ( $n=9-10 /$ group).

rats; (ii) antagonism of PAC1R via the administration of PACAP (6-38) directly into the BNST dose-dependently and selectively decreases excessive alcohol drinking only in ethanol-dependent rats; (iii) antagonism of PAC1R in the BNST blocks withdrawalinduced anxiety in ethanol-dependent rats.

Chronic ethanol exposure increases PACAP levels in the BNST but not the CeA

Our IHC data revealed an increased expression of PACAP positive fibers within the dorsal aspect of the lateral BNST (STLD) of ethanol-dependent rats during acute withdrawal from ethanol vapors, compared to control, nondependent rats. Our results in an ethanol-dependence model are consistent with previous studies which have shown increased PACAP expression in the BNST following chronic cocaine administration [44], as well as chronic variable stress [67], therefore suggesting that PACAP is recruited specifically in the BNST following chronic exposure to either stress or cycles of drug and alcohol exposure. Interestingly, acute withdrawal from chronic alcohol exposure did not affect PACAP levels in the $\mathrm{CeA}$, a brain region also part of the extended amygdala, suggesting a selective recruitment of this system in the BNST. We also show that the number of PAC1R-positive cells in the BNST of ethanol-dependent rats did not differ from that of control rats.

BNST PACAP modulates dependence-induced alcohol drinking and anxiety-like behavior

The administration of the PAC1R antagonist PACAP(6-38) into the BNST dose-dependently decreased excessive self-administration of alcohol in acutely withdrawn ethanol-dependent Wistar rats. Notably, microinfusions of PACAP(6-38) into the BNST did not affect ethanol self-administration of nondependent rats or concurrent water self-administration in either group, suggesting selectivity of action and ruling out the alternative explanation that the drug may have induced malaise or general suppressive effects on performance. Interestingly, a trend for the highest dose of PACAP(6-38) to increase self-administration in nondependent rats was observed, consistent with the anxiolytic profile of the drug and with previous results obtained from the manipulation of other anxiety-modulating systems like CRF $[51,68,69]$ and in agreement with sometimes opposing effects of PACAP under normal vs. pathological circumstances (for review, see [37]).

We then investigated whether this decreased ethanol intake observed in ethanol-dependent rats was accompanied by an anxiolytic effect of the PAC1R antagonist in the same model. We assessed this using a light-dark conflict test, a validated animal model based on the natural aversion of rodents for bright and open compartments, which is useful to predict anxiolytic-like responses [70]. While control, nondependent rats showed very low levels of anxiety following administration of vehicle or PACAP (6-38) into the BNST, spending close to $40 \%$ of the time in the open and illuminated area of the field, the ethanol-dependent rats showed instead a robust withdrawal-induced anxiety-like phenotype that resulted in only $\sim 15 \%$ of the time spent in the light compartment under vehicle conditions. This reduction was completely abolished by administration of PACAP(6-38) into the BNST. In contrast, PACAP(6-38) did not exert an anxiolytic effect on control rats. These results are in agreement with previous studies. Indeed, microinfusion of PACAP into the BNST induces a stress-like response, characterized by hypothalamic pituitary adrenal axis activation and increases in anxiety-like behavior $[21,28,30,54,67]$. A recent study observed a lack of decrease in the startle response following PACAP(6-38) administration in the BNST, but found that the antagonist attenuated the startle response following foot shock stress [31], suggesting that a previous stressor is required to see an effect of PAC1R antagonism. Our findings are also consistent with the previous observation that PACAP(6-38) administration in the BNST blocks chronic stress- 


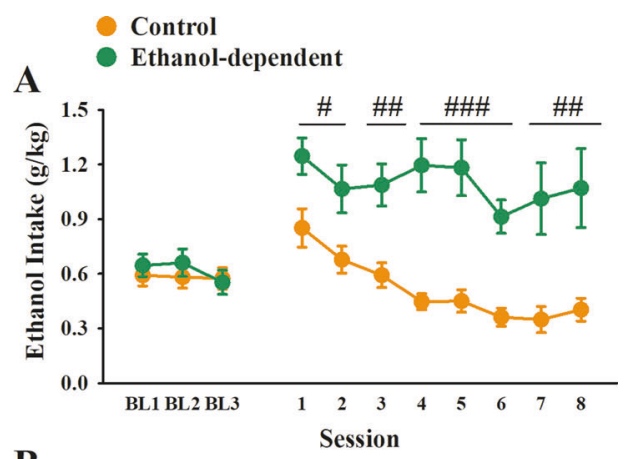

B

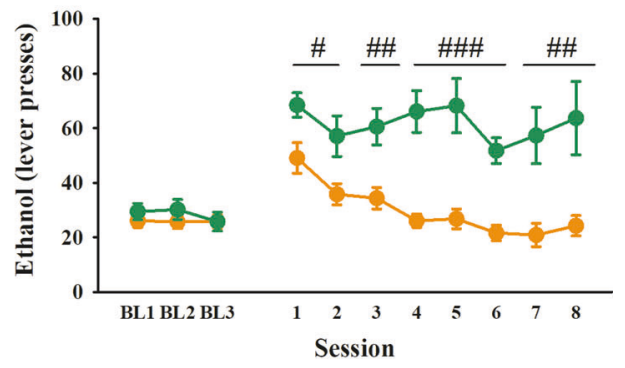

C

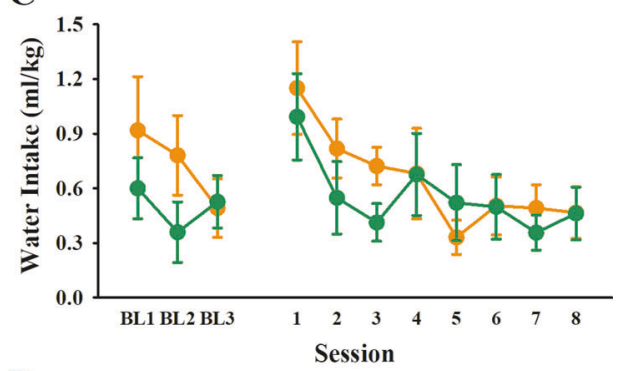

D

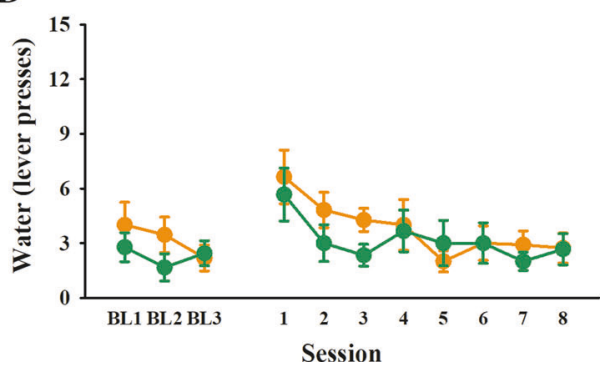

Fig. 3 Effect of chronic intermittent exposure to ethanol vapors on operant ethanol and water self-administration. Effect of chronic intermittent exposure to ethanol vapors on operant ethanol (A-B) and water (C-D) self-administration. Rats were matched for body weight and self-administration of ethanol in the last three sessions before vapor exposure (Baseline (BL) 1, 2, 3). Following 6 weeks of $\mathrm{CIE}$, ethanol-dependent rats showed increased responding for ethanol (A: $\mathrm{g} / \mathrm{kg}$; B: lever presses), but not water (C: $\mathrm{ml} / \mathrm{kg}$; D: lever presses), compared to Controls. Control and ethanoldependent rats are depicted in orange and green, respectively. Data represent Mean \pm SEM ( $n=9-12$ /group). ${ }^{\sharp} p<0.05$, ${ }^{\#} p<0.01$, $\# \#$ \#\# 0.001 vs. Controls.

induced anxiety-like behavior, while not affecting this behavior in unstressed rats [33].

BNST PACAP and the "dark side" of alcohol addiction Our findings, novel in the context of alcohol, are consistent with the notion that the PACAP/PAC1R system may represent an antireward, between-system recruited in the "dark side" of addiction
A

Control

Ethanol-dependent
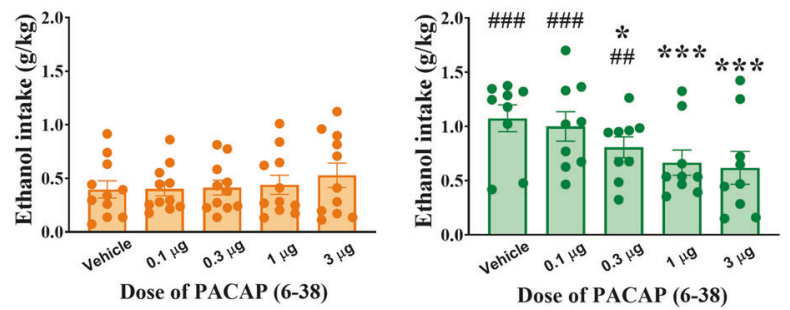

B
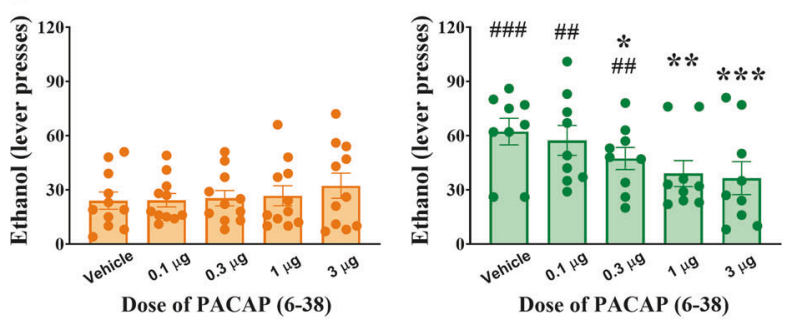

C
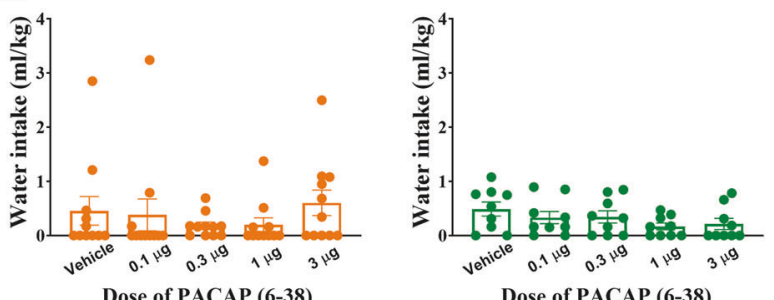

D
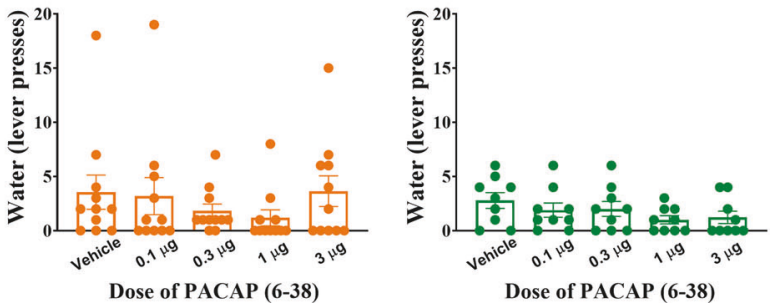

Fig. 4 Effects of intra-BNST PACAP(6-38) administration on operant ethanol and water self-administration in control and ethanol-dependent rats 8-10 $\mathrm{h}$ after ethanol vapor offset. Effects of intra-BNST PACAP(6-38) administration on operant ethanol (A-B) and water (C-D) self-administration in control, nondependent (left) and in ethanol-dependent rats (right) $8-10 \mathrm{~h}$ after ethanol vapor offset. Intra-BNST PACAP(6-38) administration did not affect ethanol self-administration in control, nondependent rats, while it significantly reduced the vapor-induced increase in ethanol selfadministration in ethanol-dependent rats (A: $\mathrm{g} / \mathrm{kg}$; B: lever presses). The drug treatment did not affect concurrent responding for water (C: $\mathrm{ml} / \mathrm{kg}$; D: lever presses). Control and ethanol-dependent rats are depicted in orange and green, respectively. Data represent Mean \pm SEM ( $n=9-12$ /group). ${ }^{*} p<0.05,{ }^{* * *} p<0.001$ vs. Vehicle, ${ }^{\#} p<0.05$, $\# \#<0.001$ vs. Controls.

$[3,37,38,71,72]$. An important study has recently found that intra-BNST PACAP(6-38) suppresses stress-induced reinstatement of cocaine seeking behavior during withdrawal, while the PAC1R agonist maxadilan facilitates reinstatement after extinction [44]. Along with our data, this suggests that the PACAP/PAC1R system in the BNST might be one of the systems suitable to manipulation to treat negative affective states during alcohol withdrawal, thereby potentially interrupting the addictive cycle [5]. PACAP (6-38) antagonism tests on self-administration and anxiety-like 
A

Control

- Ethanol-dependent

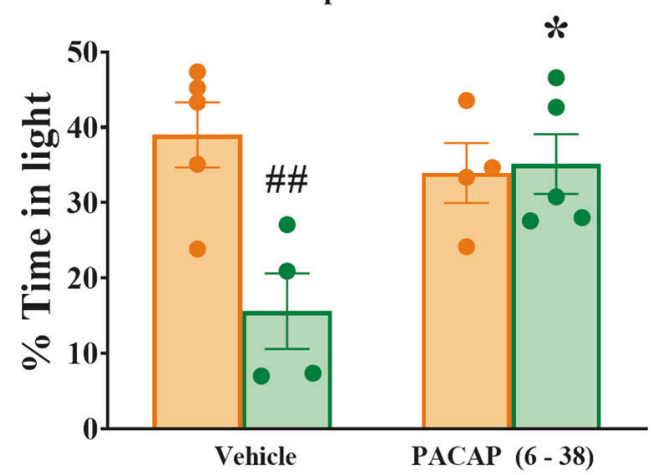

B

$$
\begin{aligned}
& \text { - Control } \\
& \text { - Ethanol-dependent }
\end{aligned}
$$

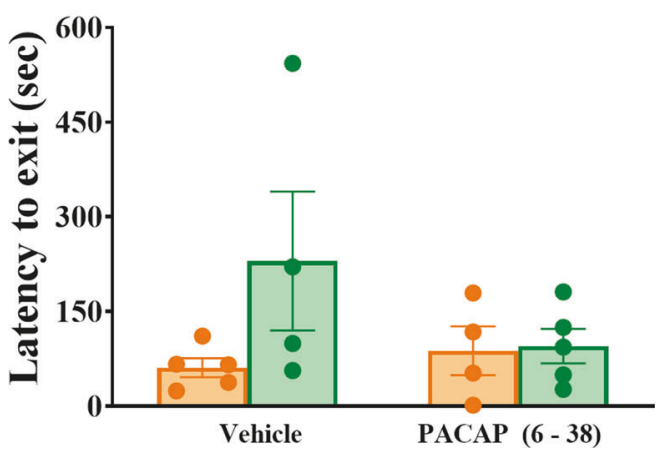

Fig. 5 Effects of intra-BNST PACAP(6-38) administration on anxiety-like behavior in the light/dark conflict test 8-10 $\mathrm{h}$ after ethanol vapor offset. Ethanol-dependent rats showed a marked reduction of the \% time spent in the aversive light compartment, compared to controls, and this decrease was completely reversed by intra-BNST administration of PACAP(6-38) (A). Latency to first exit the dark compartment was not significantly affected by the treatments (B). Control and ethanol-dependent rats are depicted in orange and green, respectively. Data represent Mean \pm SEM ( $n=4-5$ /group). ${ }^{*} p<0.05$, vs. Vehicle, ${ }^{\# \#} p<0.01$ vs. Controls.

behavior, as well as the immunohistochemical experiment, were performed at $8-10 \mathrm{~h}$ of withdrawal from intermittent vapor exposure. This acute withdrawal time point reflects when blood alcohol levels had dropped to zero and rats willingly selfadministered ethanol at high amounts and display heightened anxiety-like behavior, as shown previously [49, 73-75].

Several other stress-related peptides, including CRF, are expressed in the BNST, and contribute to the excessive alcohol intake and the emergence of negative affective states during withdrawal [1, 24, 76]. Indeed, systemic $\mathrm{CRF}_{1}$ receptor antagonists decrease ethanol self-administration in dependent, but not in control rats [51, 68, 75]. During alcohol withdrawal, extracellular CRF increases in the BNST $[77,78]$. Microinjections of CRF into the BNST have been shown to sensitize ethanol withdrawal-induced anxiety-like behavior, while $\mathrm{BNST} \mathrm{CRF}_{1}$ receptor antagonist administration alone, or prior to stress, to block this sensitization [13]. Additionally, in the same rat model used in this study, optogenetic inhibition of incoming CRF + fibers in the BNST reduces excessive ethanol consumption in ethanol-dependent rats during acute withdrawal [79]. Notably, PACAP has been proposed as an upstream regulator of CRF activation [80, 81], and the behavioral effects of PACAP administration can be blocked by CRF receptor antagonism $[21,45]$. Therefore, a deeper understanding of the precise molecular interaction between the PACAP/PAC1R system and CRF in the BNST warrants further investigation, as well as the cellular mechanisms underlying the enhancement of ethanol self-administration by enhanced PACAP activity.

Based on our data, we hypothesize that the increase in PACAP levels in the BNST during withdrawal from chronic alcohol contributes to the maintenance of excessive ethanol selfadministration and the insurgence of anxiety-like behavior through local PAC1R activation. It has previously been reported that PACAP is expressed on incoming axon terminals in the BNST [82]. These PACAP inputs to the dorsolateral subdivision of the BNST might originate from PACAP cell body populations in the paraventricular nucleus of the hypothalamus, parabrachial nucleus, CeA, medial prefrontal cortex, and/or dorsal vagal complex $[28,29,83,84]$, areas known to project to the BNST $[82,85]$. Our immunohistochemical study quantified fiber staining through densitometry and, because fibers here are very abundant, cell bodies positive for the peptide, if present, were not detectable, suggesting an upstream source of PACAP to the BNST. Future experiments will be needed to address which upstream PACAP containing nucleus is responsible for the observed effects. On the other hand, since low to moderate levels of PACAP mRNA have also been detected in punches containing the BNST of rats $[44,67]$, it is also possible that the BNST population affected by alcohol may be local.

Potential limitations of the study

PACAP can exert its effects through PAC1R, VPAC1R, and VPAC2R, though PAC1R binds PACAP with high affinity compared to VPAC receptors [86]. PAC1R is highly expressed in the BNST [87, 88], while VPAC1R and VPAC2R receptors show little expression $[89,90]$. In addition, the literature on both stress and cocaine has consistently shown a role for BNST PAC1R, but not for VPAC receptors [31-33, 44]. Therefore, even though the antagonist PACAP(6-38) is not completely selective for PAC1R over VPAC2R, we believe the effects we observed are PAC1R-mediated. However, further testing with newer, small-molecule, PAC1Rselective antagonists, or alternative tools for specifically blocking PAC1R activity should be explored.

We did not observe any reliable effect on the latency to exit in the light-dark conflict test, but only trends in both main and interaction effects. While we can confidently exclude that the main variable of the test (\% time spent in the light compartment) is sufficiently powered, as we were able to detect both main and interaction effects, it is possible that the test was not sufficiently powered for the latency, which typically tends to show higher variability.

These experiments were performed in male rats only, which is a limitation of the current study. Future studies to expand upon this work should, therefore, include investigations into sex differences. The BNST, in general, has a plethora of sexually dimorphic behavioral effects [24]; In addition, the PACAP/PAC1R system has sex-specific roles in the context of stress-related behaviors [91], and sex differences in nicotine place preference and withdrawalprecipitated anxiety- and depressive-like behavior have been reported in PACAP knockout mice [92], which highlights the need for future work on the role of PACAP in sexually dimorphic responses in addiction.

\section{CONCLUSIONS}

Our results show that $\mathrm{CIE}$ exposure induces neuroadaptations in the PACAP/PAC1R system of the BNST which mediate the heightened alcohol drinking and anxiety-like behavior observed during withdrawal. This system may, therefore, represent a promising target in the domain of restoration of reward homeostasis for the development of novel treatments for AUD. 


\section{FUNDING AND DISCLOSURE}

This publication was made possible thank to grant numbers AA026051 (PC), AA025038 (VS), and AA024439 (VS) from the National Institute on Alcohol and Alcoholism (NIAAA), and the Boston University's Undergraduate Research Opportunities Program (UROP). Its contents are solely the responsibility of the authors and do not necessarily represent the official views of the National Institutes of Health. The authors declare no conflict of interest.

\section{ACKNOWLEDGEMENTS}

We thank Lillian Huang, Tina Ta, and Rachel May Leavitt for their technical help.

\section{AUTHOR CONTRIBUTIONS}

$A F, P C$, and VS designed the experiments; AF and CVS performed the experiments; AF and MAM analyzed the data; $\mathrm{AF}$ and MAM wrote a first draft of the manuscript, all authors edited the manuscript and approved the final version.

\section{ADDITIONAL INFORMATION}

Supplementary Information accompanies this paper at (https://doi.org/10.1038/ s41386-020-00904-4).

Publisher's note Springer Nature remains neutral with regard to jurisdictional claims in published maps and institutional affiliations.

\section{REFERENCES}

1. Heilig M, Koob GF. A key role for corticotropin-releasing factor in alcohol dependence. Trends Neurosci. 2007;30:399-406.

2. Dackis C, O'Brien C. Neurobiology of addiction: treatment and public policy ramifications. Nat Neurosci. 2005;8:1431-6.

3. Koob GF. The dark side of emotion: the addiction perspective. Eur J Pharm. 2015;753:73-87.

4. Koob GF, Schulkin J. Addiction and stress: an allostatic view. Neurosci Biobehav Rev. 2019;106:245-62.

5. Breese GR, Sinha R, Heilig M. Chronic alcohol neuroadaptation and stress contribute to susceptibility for alcohol craving and relapse. Pharm Ther. 2011;129:149-71.

6. Pleil KE, Rinker JA, Lowery-Gionta EG, Mazzone CM, McCall NM, Kendra AM, et al. NPY signaling inhibits extended amygdala CRF neurons to suppress binge alcohol drinking. Nat Neurosci. 2015;18:545-52.

7. Koob GF, Volkow ND. Neurobiology of addiction: a neurocircuitry analysis. Lancet Psychiatry. 2016;3:760-73.

8. Avery SN, Clauss JA, Blackford JU. The human BNST: functional role in anxiety and addiction. Neuropsychopharmacology. 2016;41:126-41.

9. Kash TL, Baucum AJ,2nd, Conrad KL, Colbran RJ, Winder DG. Alcohol exposure alters NMDAR function in the bed nucleus of the stria terminalis. Neuropsychopharmacology. 2009;34:2420-9.

10. McElligott ZA, Winder DG. Modulation of glutamatergic synaptic transmission in the bed nucleus of the stria terminalis. Prog Neuro-Psychopharmacol Biol psychiatry. 2009;33:1329-35.

11. Harris NA, Winder DG. Synaptic plasticity in the bed nucleus of the stria terminalis: underlying mechanisms and potential ramifications for reinstatement of drug- and alcohol-seeking behaviors. ACS Chem Neurosci. 2018;9:2173-87.

12. Pati D, MarcinkiewCz CA, DiBerto JF, Cogan ES, McElligott ZA, Kash TL. Chronic intermittent ethanol exposure dysregulates a GABAergic microcircuit in the bed nucleus of the stria terminalis. Neuropharmacology. 2020;168:107759.

13. Huang MM, Overstreet $D H$, Knapp DJ, Angel R, Wills TA, Navarro $M$, et al. Corticotropin-releasing factor (CRF) sensitization of ethanol withdrawal-induced anxiety-like behavior is brain site specific and mediated by CRF-1 receptors: relation to stress-induced sensitization. J Pharm Exp Ther. 2010;332:298-307.

14. Kwako LE, Koob GF. Neuroclinical framework for the role of stress in addiction. Chronic Stress. 2017;1:1-14.

15. Aston-Jones G, Kalivas PW. Brain norepinephrine rediscovered in addiction research. Biol Psychiatry. 2008;63:1005-6.

16. Logrip ML, Koob GF, Zorrilla EP. Role of corticotropin-releasing factor in drug addiction: potential for pharmacological intervention. CNS Drugs. 2011;25: 271-87.
17. Kash TL, Pleil KE, MarcinkiewCz CA, Lowery-Gionta EG, Crowley N, Mazzone C, et al. Neuropeptide regulation of signaling and behavior in the BNST. Mol Cells. 2015;38:1-13.

18. Marcinkiewcz CA, Dorrier CE, Lopez AJ, Kash TL. Ethanol induced adaptations in $5-\mathrm{HT} 2 \mathrm{C}$ receptor signaling in the bed nucleus of the stria terminalis: implications for anxiety during ethanol withdrawal. Neuropharmacology. 2015;89:157-67.

19. MarcinkiewCz CA, Mazzone CM, D'Agostino G, Halladay LR, Hardaway JA, DiBerto $\mathrm{JF}$, et al. Serotonin engages an anxiety and fear-promoting circuit in the extended amygdala. Nature. 2016;537:97-101.

20. lemolo A, Seiglie M, Blasio A, Cottone P, Sabino V. Pituitary adenylate cyclaseactivating polypeptide (PACAP) in the central nucleus of the amygdala induces anxiety via melanocortin receptors. Psychopharmacology (Berl). 2016;233: 3269-77. https://doi.org/10.1007/s00213-016-4366-y.

21. Dore R, lemolo A, Smith KL, Wang X, Cottone P, Sabino V. CRF mediates the anxiogenic and anti-rewarding, but not the anorectic effects of PACAP. Neuropsychopharmacology. 2013;38:2160-9.

22. Hammack SE, May V. Pituitary adenylate cyclase activating polypeptide in stressrelated disorders: data convergence from animal and human studies. Biol Psychiatry. 2015;78:167-77.

23. Varodayan FP, Minnig MA, Steinman MQ, Oleata CS, Riley MW, Sabino V, et al. PACAP regulation of central amygdala GABAergic synapses is altered by restraint stress. Neuropharmacology. 2020;168:107752.

24. Lebow MA, Chen A. Overshadowed by the amygdala: the bed nucleus of the stria terminalis emerges as key to psychiatric disorders. Mol Psychiatry. 2016;21:450-63.

25. Palkovits $M$, Somogyvari-Vigh A, Arimura A. Concentrations of pituitary adenylate cyclase activating polypeptide (PACAP) in human brain nuclei. Brain Res. 1995;699:116-20.

26. Piggins HD, Stamp JA, Burns J, Rusak B, Semba K. Distribution of pituitary adenylate cyclase activating polypeptide (PACAP) immunoreactivity in the hypothalamus and extended amygdala of the rat. J Comp Neurol. 1996;376:278-94.

27. Hannibal J. Pituitary adenylate cyclase-activating peptide in the rat central nervous system: an immunohistochemical and in situ hybridization study. J Comp Neurol. 2002;453:389-417.

28. Missig G, Roman CW, Vizzard MA, Braas KM, Hammack SE, May V. Parabrachial nucleus (PBn) pituitary adenylate cyclase activating polypeptide (PACAP) signaling in the amygdala: implication for the sensory and behavioral effects of pain. Neuropharmacology. 2014;86:38-48.

29. Missig G, Mei L, Vizzard MA, Braas KM, Waschek JA, Ressler KJ, et al. Parabrachial pituitary adenylate cyclase-activating polypeptide activation of amygdala endosomal extracellular signal-regulated kinase signaling regulates the emotional component of pain. Biol Psychiatry. 2017;81:671-82.

30. Agarwal A, Halvorson LM, Legradi G. Pituitary adenylate cyclase-activating polypeptide (PACAP) mimics neuroendocrine and behavioral manifestations of stress: Evidence for PKA-mediated expression of the corticotropin-releasing hormone (CRH) gene. Brain Res Mol Brain Res. 2005;138:45-57.

31. Seiglie MP, Huang L, Cottone P, Sabino V. Role of the PACAP system of the extended amygdala in the acoustic startle response in rats. Neuropharmacology. 2019;160:107761.

32. Lezak KR, Roman CW, Braas KM, Schutz KC, Falls WA, Schulkin J, et al. Regulation of bed nucleus of the stria terminalis PACAP expression by stress and corticosterone. J Mol Neurosci. 2014;54:477-84.

33. Roman CW, Lezak KR, Hartsock MJ, Falls WA, Braas KM, Howard AB, et al. PAC1 receptor antagonism in the bed nucleus of the stria terminalis (BNST) attenuates the endocrine and behavioral consequences of chronic stress. Psychoneuroendocrinology. 2014;47:151-65.

34. Kovanen L, Saarikoski ST, Haukka J, Pirkola S, Aromaa A, Lonnqvist J, et al. Circadian clock gene polymorphisms in alcohol use disorders and alcohol consumption. Alcohol Alcohol. 2010;45:303-11.

35. Dragan WL, Czerski PM, Dragan M. PAC1 receptor (ADCYAP1R1) genotype and problematic alcohol use in a sample of young women. Neuropsychiatr Dis Treat. 2017;13:1483-89.

36. Marquez P, Bebawy D, Lelievre V, Coute AC, Evans CJ, Waschek JA, et al. The role of endogenous PACAP in motor stimulation and conditioned place preference induced by morphine in mice. Psychopharmacology. 2009;204:457-63.

37. Gargiulo AT, Curtis GR, Barson JR. Pleiotropic pituitary adenylate cyclaseactivating polypeptide (PACAP): Novel insights into the role of PACAP in eating and drug intake. Brain Res. 2020;1729:146626.

38. Stojakovic A, Ahmad SM, Malhotra S, Afzal Z, Ahmed M, Lutfy K. The role of pituitary adenylyl cyclase-activating polypeptide in the motivational effects of addictive drugs. Neuropharmacology. 2020;171:108109.

39. Feany MB, Quinn WG. A neuropeptide gene defined by the Drosophila memory mutant amnesiac. Science. 1995:268:869-73. 
40. Tanaka K, Hashimoto H, Shintani N, Yamamoto A, Baba A. Reduced hypothermic and hypnotic responses to ethanol in PACAP-deficient mice. Regul Pept. 2004;123:95-8.

41. Tanaka K, Kunishige-Yamamoto A, Hashimoto $H$, Shintani N, Hayata A, Baba A Increased ethanol preference and serotonin $1 \mathrm{~A}$ receptor-dependent attenuation of ethanol-induced hypothermia in PACAP-deficient mice. Biochem Biophys Res Commun. 2010;391:773-7.

42. He DY, Vagts AJ, Yaka R, Ron D. Ethanol induces gene expression via nuclear compartmentalization of receptor for activated $\mathrm{C}$ kinase 1. Mol Pharm 2002;62:272-80.

43. Gupta A, Gargiulo AT, Curtis GR, Badve PS, Pandey S, Barson JR. Pituitary adenylate cyclase-activating polypeptide-27 (PACAP-27) in the thalamic paraventricular nucleus is stimulated by ethanol drinking. Alcohol Clin Exp Res. 2018;42:1650-60.

44. Miles OW, Thrailkill EA, Linden AK, May V, Bouton ME, Hammack SE. Pituitary adenylate cyclase-activating peptide in the bed nucleus of the stria terminalis mediates stress-induced reinstatement of cocaine seeking in rats. Neuropsychopharmacology. 2018;43:978-86.

45. Seiglie MP, Smith KL, Blasio A, Cottone P, Sabino V. Pituitary adenylate cyclaseactivating polypeptide induces a depressive-like phenotype in rats. Psychopharmacology. 2015;232:3821-31.

46. Burgos JR, Iresjo BM, Smedh U. Pituitary adenylate cyclase-activating polypeptide 6-38 blocks cocaine- and amphetamine-regulated transcript Peptide-induced hypophagia in rats. PLoS ONE. 2013;8:e72347.

47. Telegdy G, Adamik A. Neurotransmitter-mediated anxiogenic action of PACAP-38 in rats. Behav Brain Res. 2015;281:333-8.

48. Sabino V, Cottone P, Blasio A, lyer MR, Steardo L, Rice KC, et al. Activation of sigma-receptors induces binge-like drinking in Sardinian alcohol-preferring rats. Neuropsychopharmacology. 2011;36:1207-18.

49. Sabino V, Cottone P, Zhao Y, lyer MR, Steardo L Jr., Steardo L, et al. The sigmareceptor antagonist BD-1063 decreases ethanol intake and reinforcement in animal models of excessive drinking. Neuropsychopharmacology. 2009;34:1482-93.

50. O'Dell LE, Roberts AJ, Smith RT, Koob GF. Enhanced alcohol self-administration after intermittent versus continuous alcohol vapor exposure. Alcohol Clin Exp Res. 2004;28:1676-82.

51. Funk CK, Zorrilla EP, Lee MJ, Rice KC, Koob GF. Corticotropin-releasing factor 1 antagonists selectively reduce ethanol self-administration in ethanol-dependent rats. Biol Psychiatry. 2007;61:78-86.

52. lemolo A, Ferragud A, Cottone P, Sabino V. Pituitary Adenylate Cyclase-Activating Peptide in the Central Amygdala Causes Anorexia and Body Weight Loss via the Melanocortin and the TrkB Systems. Neuropsychopharmacology. 2015;40: 1846-55. https://doi.org/10.1038/npp.2015.34.

53. lemolo A, Blasio A,St, Cyr SA, Jiang F, Rice KC, Sabino V, et al. CRF-CRF1 receptor system in the central and basolateral nuclei of the amygdala differentially mediates excessive eating of palatable food. Neuropsychopharmacology. 2013;38:2456-66.

54. Norrholm SD, Das M, Legradi G. Behavioral effects of local microinfusion of pituitary adenylate cyclase activating polypeptide (PACAP) into the paraventricular nucleus of the hypothalamus (PVN). Regul Pept. 2005;128:33-41.

55. Das $M$, Vihlen CS, Legradi G. Hypothalamic and brainstem sources of pituitary adenylate cyclase-activating polypeptide nerve fibers innervating the hypothalamic paraventricular nucleus in the rat. J Comp Neurol. 2007;500:761-76.

56. Liu Q, Wong-Riley MTT. Pituitary adenylate cyclase-activating polypeptide: postnatal development in multiple brain stem respiratory-related nuclei in the rat. Respir Physiol Neurobiol. 2019;259:149-55.

57. Nakamura K, Nakamachi T, Endo K, Ito K, Machida T, Oka T, et al. Distribution of pituitary adenylate cyclase-activating polypeptide (PACAP) in the human testis and in testicular germ cell tumors. Andrologia. 2014;46:465-71.

58. Matsumoto $M$, Nakamachi T, Watanabe J, Sugiyama $K$, Ohtaki $H$, Murai $N$, et al. Pituitary adenylate cyclase-activating polypeptide (PACAP) is involved in adult mouse hippocampal neurogenesis after stroke. J Mol Neurosci. 2016;59:270-9.

59. Meloni EG, Kaye KT, Venkataraman A, Carlezon WA Jr. PACAP increases Arc/Arg 3.1 expression within the extended amygdala after fear conditioning in rats. Neurobiol Learn Mem. 2019;157:24-34.

60. Csati A, Tajti J, Kuris A, Tuka B, Edvinsson L, Warfvinge K. Distribution of vasoactive intestinal peptide, pituitary adenylate cyclase-activating peptide, nitric oxide synthase, and their receptors in human and rat sphenopalatine ganglion. Neuroscience. 2012;202:158-68.

61. Steinberg A, Frederiksen SD, Blixt FW, Warfvinge K, Edvinsson L. Expression of messenger molecules and receptors in rat and human sphenopalatine ganglion indicating therapeutic targets. J Headache Pain. 2016;17:78.

62. Castorina A, Scuderi S, D'Amico AG, Drago F, D'Agata V. PACAP and VIP increase the expression of myelin-related proteins in rat schwannoma cells: involvement of PAC1/VPAC2 receptor-mediated activation of PI3K/Akt signaling pathways. Exp Cell Res. 2014;322:108-21.

63. Giunta S, Castorina A, Bucolo C, Magro G, Drago F, D'Agata V. Early changes in pituitary adenylate cyclase-activating peptide, vasoactive intestinal peptide and related receptors expression in retina of streptozotocin-induced diabetic rats. Peptides. 2012;37:32-9.

64. Han X, Ran Y, Su M, Liu Y, Tang W, Dong Z, et al. Chronic changes in pituitary adenylate cyclase-activating polypeptide and related receptors in response to repeated chemical dural stimulation in rats. Mol Pain. 2017;13: 1744806917720361.

65. Ferragud A, Velazquez-Sanchez C, Abdullatif AA, Sabino V, Cottone P. Withdrawal from extended, intermittent access to a highly palatable diet impairs hippocampal memory function and neurogenesis: effects of memantine. Nutrients. 2020;12.

66. Paxinos G, Watson C. The Rat brain in stereotaxic coordinates. 6th edn. Elsevier Academic Press; 2007.

67. Hammack SE, Cheung J, Rhodes KM, Schutz KC, Falls WA, Braas KM, et al. Chronic stress increases pituitary adenylate cyclase-activating peptide (PACAP) and brainderived neurotrophic factor (BDNF) mRNA expression in the bed nucleus of the stria terminalis (BNST): roles for PACAP in anxiety-like behavior. Psychoneuroendocrinology. 2009;34:833-43.

68. Gilpin NW, Richardson HN, Koob GF. Effects of CRF1-receptor and opioid-receptor antagonists on dependence-induced increases in alcohol drinking by alcoholpreferring (P) rats. Alcohol Clin Exp Res. 2008;32:1535-42.

69. Zorrilla EP, Logrip ML, Koob GF. Corticotropin releasing factor: a key role in the neurobiology of addiction. Front Neuroendocrinol. 2014:35:234-44.

70. Crawley J, Goodwin FK. Preliminary report of a simple animal behavior model for the anxiolytic effects of benzodiazepines. Pharmacol Biochem Behav. 1980;13:167-70.

71. Lutfy K, Shankar G. Emerging evidence for the role of pituitary adenylate cyclaseactivating peptide in neuropsychiatric disorders. Prog Mol Biol Transl Sci. 2019;167:143-57.

72. Koob GF. Addiction is a reward deficit and stress surfeit disorder. Front Psychiatry. 2013;4:72.

73. Roberts AJ, Cole M, Koob GF. Intra-amygdala muscimol decreases operant ethanol self-administration in dependent rats. Alcohol Clin Exp Res. 1996;20:1289-98.

74. Vendruscolo LF, Roberts AJ. Operant alcohol self-administration in dependent rats: focus on the vapor model. Alcohol. 2014;48:277-86.

75. Sabino V, Cottone P, Koob GF, Steardo L, Lee MJ, Rice KC, et al. Dissociation between opioid and CRF1 antagonist sensitive drinking in Sardinian alcoholpreferring rats. Psychopharmacology. 2006;189:175-86

76. Holmes A, Heilig M, Rupniak NM, Steckler T, Griebel G. Neuropeptide systems as novel therapeutic targets for depression and anxiety disorders. Trends Pharm Sci. 2003;24:580-8.

77. Silberman Y, Matthews RT, Winder DG. A corticotropin releasing factor pathway for ethanol regulation of the ventral tegmental area in the bed nucleus of the stria terminalis. J Neurosci. 2013;33:950-60.

78. Olive MF, Koenig HN, Nannini MA, Hodge CW. Elevated extracellular CRF levels in the bed nucleus of the stria terminalis during ethanol withdrawal and reduction by subsequent ethanol intake. Pharmacol Biochem Behav. 2002;72:213-20.

79. de Guglielmo G, Kallupi M, Pomrenze MB, Crawford E, Simpson S, Schweitzer P, et al. Inactivation of a CRF-dependent amygdalofugal pathway reverses addiction-like behaviors in alcohol-dependent rats. Nat Commun. 2019;10:1238.

80. Miles OW, May V, Hammack SE. Pituitary adenylate cyclase-activating peptide (PACAP) signaling and the dark side of addiction. J Mol Neurosci. 2019;68:453-64.

81. Tsukiyama N, Saida Y, Kakuda M, Shintani N, Hayata A, Morita Y, et al. PACAP centrally mediates emotional stress-induced corticosterone responses in mice. Stress. 2011;14:368-75.

82. Kozicz T, Vigh S, Arimura A. Axon terminals containing PACAP- and VIPimmunoreactivity form synapses with CRF-immunoreactive neurons in the dorsolateral division of the bed nucleus of the stria terminalis in the rat. Brain Res. 1997;767:109-19.

83. Legradi G, Shioda S, Arimura A. Pituitary adenylate cyclase-activating polypeptide-like immunoreactivity in autonomic regulatory areas of the rat medulla oblongata. Neurosci Lett. 1994;176:193-6.

84. Kirry AJ, Herbst MR, Poirier SE, Maskeri MM, Rothwell AC, Twining RC, et al. Pituitary adenylate cyclase-activating polypeptide (PACAP) signaling in the prefrontal cortex modulates cued fear learning, but not spatial working memory, in female rats. Neuropharmacology. 2018;133:145-54.

85. Weller KL, Smith DA. Afferent connections to the bed nucleus of the stria terminalis. Brain Res. 1982;232:255-70. 
Pituitary adenylate cyclase-activating polypeptide (PACAP) modulates...

A Ferragud et al.

518

86. Harmar AJ, Fahrenkrug J, Gozes I, Laburthe M, May V, Pisegna JR, et al. Pharmacology and functions of receptors for vasoactive intestinal peptide and pituitary adenylate cyclase-activating polypeptide: IUPHAR review 1. Br J Pharm. 2012;166:4-17.

87. Jaworski DM, Proctor MD. Developmental regulation of pituitary adenylate cyclase-activating polypeptide and PAC(1) receptor mRNA expression in the rat central nervous system. Brain Res Dev Brain Res. 2000;120:27-39.

88. Hashimoto $H$, Nogi $H$, Mori K, Ohishi H, Shigemoto R, Yamamoto K, et al. Distribution of the mRNA for a pituitary adenylate cyclase-activating polypeptide receptor in the rat brain: an in situ hybridization study. J Comp Neurol. 1996:371:567-77.
89. Ishihara T, Shigemoto R, Mori K, Takahashi K, Nagata S. Functional expression and tissue distribution of a novel receptor for vasoactive intestinal polypeptide. Neuron. 1992;8:811-9.

90. Sheward WJ, Lutz EM, Harmar AJ. The distribution of vasoactive intestinal peptide2 receptor messenger RNA in the rat brain and pituitary gland as assessed by in situ hybridization. Neuroscience. 1995;67:409-18.

91. King SB, Toufexis DJ, Hammack SE. Pituitary adenylate cyclase activating polypeptide (PACAP), stress, and sex hormones. Stress. 2017;20:465-75.

92. Nega S, Marquez P, Hamid A, Ahmad SM, Lutfy K. The role of pituitary adenylyl cyclase activating polypeptide in affective signs of nicotine withdrawal. J Neurosci Res. 2020;98:1549-60. 